\title{
LONG TERM HEALTH MONITORING OF POST-TENSIONING BOX GIRDER BRIDGES
}

\author{
Ming L. Wang ${ }^{1}$
}

\begin{abstract}
$\underline{\text { Abstract }}$
A number of efforts had been sought to instrument bridges for the purpose of structural monitoring and assessment. The outcome of these efforts, as gauged by advances in the understanding of the definition of structural damage and their role in sensor selection as well as in the design of cost and data-effective monitoring systems, has itself been difficult to assess. The authors' experience with the design, calibration, and operation of a monitoring system for the Kishwaukee Bridge in Illinois has provided several lessons that bear upon these concerns. The systems have performed well in providing a continuous, low-cost monitoring platform for bridge engineers with immediate relevant information. Experiences learned from the design and installation of health monitoring systems for several major long span bridges in Japan and China will be addressed.
\end{abstract}

\section{$\underline{\text { Introduction }}$}

Bridges play an essential part of a highway network. They are open to traffic, resistant to natural disaster, and undaunted by millions of loading cycles per year. However, this fortitude is quite expensive to maintain and do occasionally fail1. The fact that many bridges are carrying greater average loads than predicted during their design has significantly increased the need to monitor bridge performance over the past few years. To effectively manage bridges today, there is a great need to monitor the real-time conditions of bridges, and the deterioration rates of their components, so that efficient and pro-active measures can be taken3-6. By using the latest state-of-the-art technologies, it is possible to utilize health monitoring systems on highway bridges to determine their behavior and condition, and promote a response to maintenance and inspection needs2.

Bridge health monitoring systems have historically been implemented for the pur pose of understanding bridge behavior under various loads and environmental effects7-12 . One of the earliest documented bridge monitoring exercises was conducted on the Gold en Gate and Bay Bridges in San Francisco to learn about the dynamic behavior and possi ble consequences of earthquakes by Carder (1937)13. Carder's studies were applied to th e probability analysis of damage caused by resonance during seismic excitation. The exp erimental procedure consisted of measuring ambient vibration data provided by a photogr aphic seismograph that was attached to the bridge. Wind, moving water, traffic, or people working on the bridges caused the recorded vibrations. Studies of wind-induced vibratio n on the Golden Gate bridge are summarized by Vincent (1958)14. Vincent discussed the

\footnotetext{
${ }^{1}$ Professor, University of Illinois- Chicago, Chicago, IL 60607, USA
} 
development of a mechanical accelerometer specifically for this bridge and obtained mea surements to verify that structural modifications to the bridge would prevent objectionabl e torsional vibrations.

With the development of design theories and construction techniques for long-spa $\mathrm{n}$ bridges, a lot of large bridges were built during the last fifty years. For the safety of the se giants, some long-term bridge monitoring systems were developed and installed. The $t$ ypical examples are Commodore Barry Bridge Monitoring System (USA), Jindao Grand Bridge Monitoring System (Korea), Akashi Kaikyo Bridge Monitoring System (Japan), Alamillo Bridge Monitoring System (Spain), Hummer Bridge Monitoring System (UK), and Zhanjiang Bay Bridge Monitoring System (China), etc. In all of the long-term monito ring systems, the most extensively deviced one is the Wind and Structural Health Monito ring System (WASHMS) for Tsingma Bridge in Hong Kong, which sensory system consi sts of approximately 350 sensors and their relevant interfacing units, including the latest GPS system.

However, the current long-term bridge monitoring systems lack the specific techniques to provide reliable diagnosis information of bridge condition. Most of these monitoring systems can only collect data from the sensor network and perform some simple data processing. The work of analysis and assessment has to be done manually by human specialists with the help of different independent analysis tools. For a real-time monitoring system, such as WASHMS, the huge amount of data daily collected with a high sampling rate (e.g., $100 \mathrm{~Hz}$ ) will overwhelm the computers of those bridge engineers and make the evaluation difficult and inefficient. This paper will provide a supplement to the current research on bridge health monitoring and improve the understanding of bridge behavior.

\section{Kishwaukee Bridge Monitoring}

Kishwaukee River Bridge (Rockford, IL) is a post-tensioned precast segmental concrete box-girder bridge opened to traffic in 1980. The bridge has five spans with lengths of $170 \mathrm{ft}+3 \times 250 \mathrm{ft}+170 \mathrm{ft}(51.8 \mathrm{~m}+3 \times 76.2 \mathrm{~m}+51.8 \mathrm{~m})$. As the first-generation of segmental structures, the Kishwaukee Bridge engineers chose the design of a single shear-key joint usually located close to the centroid of the cross-section. These joints are quite vulnerable especially during polymerization of the glue.

A very serious problem arose after completion of the bridge. It was found out that epoxy did not harden properly in the most of the joints. The epoxy was not able to carry any shear stresses and instead was acting as a lubricant that caused reduction of friction c oefficient. Therefore a substantial part of the shear force was concentrated at the shear ke

$\mathrm{ys}^{15}$. As shown in Figure 1, the inclined cracks went through the joint because the horizo ntal 


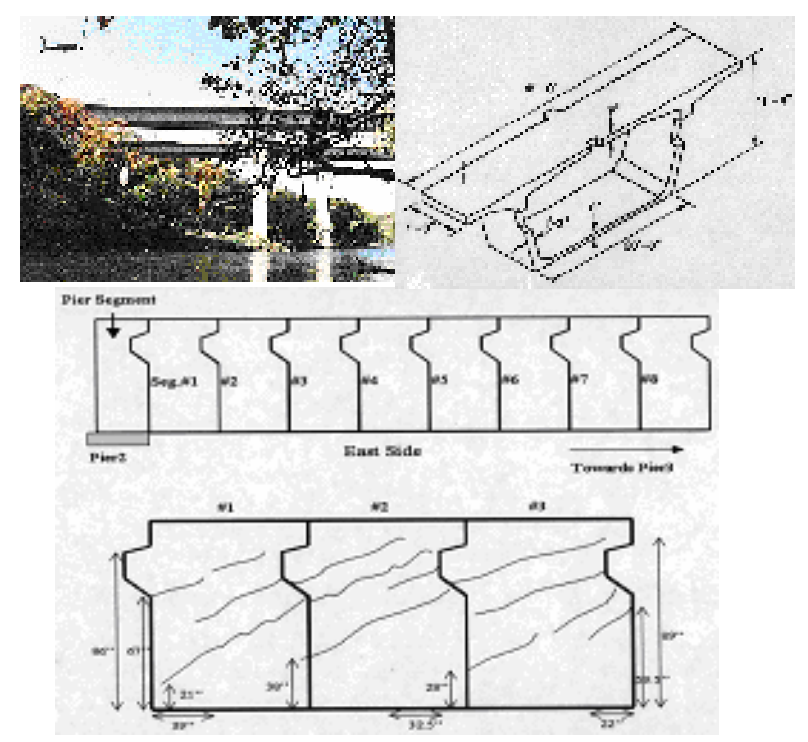

Figure 1 Shear cracks on the webs of Kishwaukee bridge

length of the compression struts was limited to the length of one segment. After bridge en gineers found the cracking problem, many steel pins were used on the webs to stop the pr opagation of shear cracks. It proves successful by now. However, nobody knows if the sh ear cracks will not propagate for the future. Therefore, a long-term monitoring system is i ndispensable and should be installed for structural surveillance of the Kishwaukee Bridge to provide continuous health records for the bridge management department ${ }^{16}$.

Since the major problem of Kishwaukee Bridge is shear cracks on the webs, a specifically designed structural health monitoring system was installed on the Kishwaukee Southbound Bridge ${ }^{17}$. This system monitors and records the strain, crack opening displacement, and acceleration of the bridge, as well as the temperature outside and inside the bridge girder. Thus, the operation and management for this bridge is transformed into a more objective and quantitative process. This process provides for optimal integration of experimental, analytical, and informational system components ${ }^{18}$. In addition, the outcome of the process provides valuable information for current evaluation of structural integrity, durability, and reliability ${ }^{19}$. Using this information, composed from the sensory system, data acquisition system, and health assessment system, the bridge owner and maintenance authorities can make rational decisions in assigning the budgets for both maintenance and repair.

\section{Static load test}

In order to determine actual health status of Kishwaukee Southbound Bridge and set up the baseline for the following long-term health monitoring, we did two static load $\mathrm{t}$ ests in 2000. The bridge was tested for service loading conditions. The weight of the truc ks 

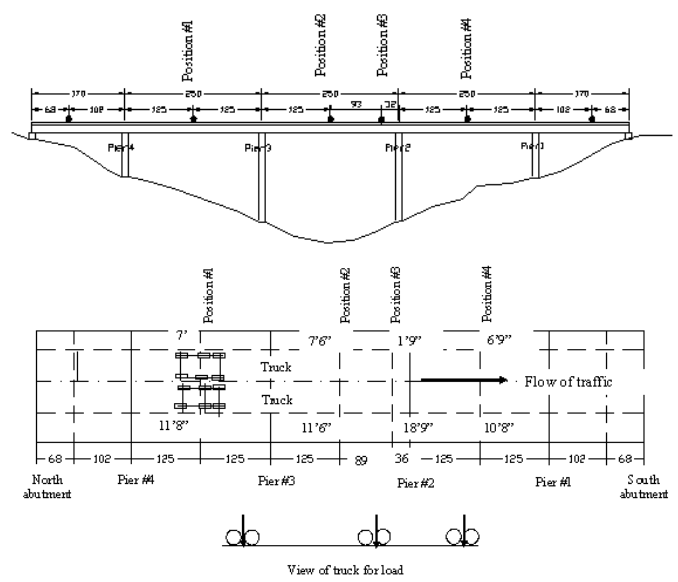

Figure 2 Static diagnosis load test on the southbound Kishwaukee bridge

was comparable with a weight of the design truck defined in AASHTO LRFD Bridge Design Specifications. The design weight of the truck (72 kips) was amplified by a dynamic factor of $\delta=1.320$. Four different positions of the trucks were proposed on the bridge, as shown in Figure 2.

Visual inspection of the shear cracks determined the most damaged webs in the bridge. Web SB2-N4-E was chosen for in-situ measurement of deformation due to shear forces. Three linear variable displacement transducers (LVDT) were installed at the interior surface of the web, close to the neutral axis, as shown in Figure 3. Measured displacements were used for estimation of the web's shear stiffness. The load stage using trucks located in position \#2 (second load) was selected for assessment, because neither transverse bending moments nor vertical axial stresses accompanied the imposed load in the web of segment SB2-N4. Shear forces generated by trucks located in position \#3 (second load) were used for calculation of the steel stress increment in reinforcement.
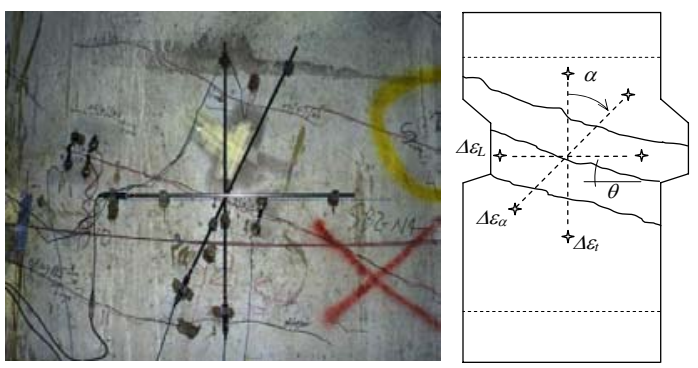

Figure 3 LVDT sensors installed on the inner surface of the web

Average shear strain and shear stiffness of the cracked web:

$$
\Delta \gamma_{L t}=\frac{2\left[\Delta \varepsilon_{\alpha}-\Delta \varepsilon_{L} \sin ^{2}(\alpha)-\Delta \varepsilon_{t} \cos ^{2}(\alpha)\right]}{2 \cos (\alpha) \sin (\alpha)}
$$




$$
(G A)_{i r}=\frac{\Delta V}{\Delta \gamma_{L t}}
$$

To determine the global flexural stiffness of the bridge, strain gauges were installed at the webs of segments located next to the closures. Measured concrete strains were used for calculation of curvature in Eq. 3 and evaluation of the modulus by Eq. 4:

$$
\begin{aligned}
& \Delta \chi_{\text {meas }}=\left(\Delta \varepsilon_{\text {upper }}-\Delta \varepsilon_{\text {lower }}\right) / d_{g s} \\
& E_{c}=\Delta M /\left(\Delta \chi_{\text {meas }} I_{i}\right)
\end{aligned}
$$

The assessed value of modulus was still in the range from 35,000 MPa to 40,000 MPa. This value is very similar to the design value, while the tangent shear modulus has been reduced about $50-55 \%$ by shear cracks. Therefore the change of bridge shear stiffness has little influence on its flexural stiffness. Dynamic tests and FEM simulation also corroborate the negligible effect of shear stiffness on flexural stiffness.

\section{Half-scale experiment of concrete girder}

In order to determine the shear carrying capacity of Kishwaukee Bridge, a half-sc ale I-beam model was cast in the Lab. The following parameters are measured in this exp eriment: Deflection of the end of cantilever; Flange strains; Web strains; Reinforcement s trains; Prestressing force; Elongation of the strands.

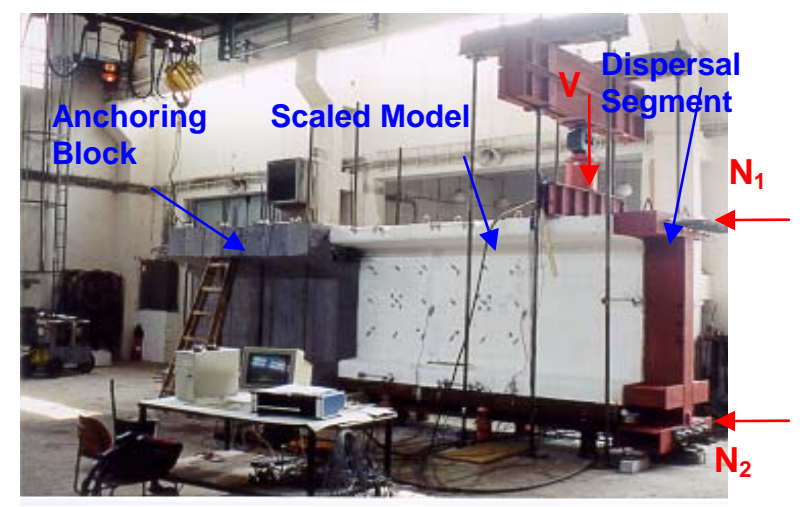

Figure 4 Arrangement of half-scale experiment

Figure 4 presents the arrangement of the half-scale experiment. The three half-scale I-beam segments were put between the anchoring block and the dispersal segment. 


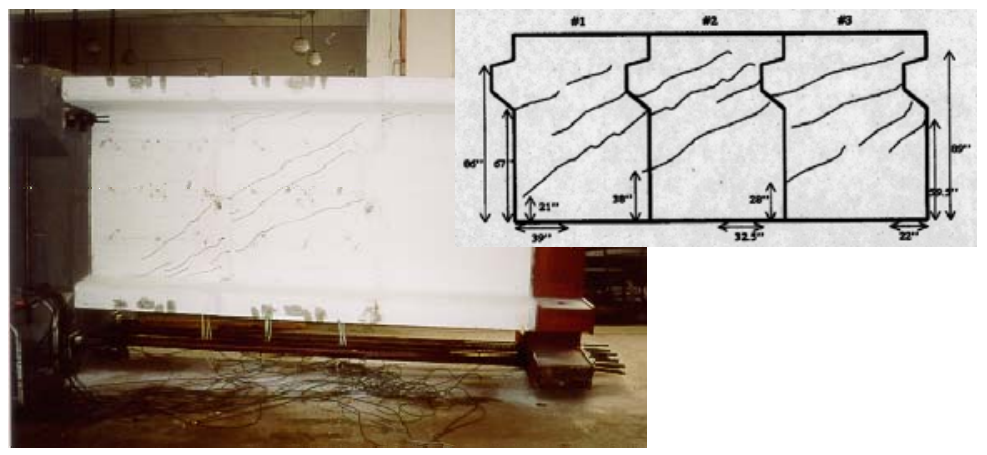

Figure 5 Propagation of shear cracks on the i-beam

The friction between the joints of three segments was reduced to a certain degree $t$ o simulate the unhardened epoxy problem on the southbound Kishwaukee Bridge. The pr estressing reinforcement was delivered by the low relaxation strands with a high yielding point of $1800 \mathrm{MPa}$. The upper prestressing force N1 was applied with eight 3-strand tend ons in the top flange while four 4-strand tendons were used to apply the lower prestressin $\mathrm{g}$ force $\mathrm{N} 2$ under the bottom flange. The shear force $\mathrm{V}$ was applied with a hydraulic jack.

The propagation of shear cracks on the I-beam webs is shown in Figure 5. Accord ing to the visual inspection records, the type and inclination of these shear cracks are simi lar to the actual cracks on the Kishwaukee Bridge. It indicates the experiment successfull y simulated the actual damage condition of Kishwaukee Bridge. The relationship of shear stress and shear strain is shown in Figure 6. After the linear elastic phase, the concrete $\mathrm{cr}$ acked and the steel reinforcement carried much of the shear force itself, which is evident from the graph. About the yielding point of shear reinforcement, the reduced tangent shea r modulus was roughly $5300 \mathrm{MPa}$. According to the analysis of the static load test, the $\mathrm{cu}$ rrent tangent shear modulus is approximately $6740 \mathrm{MPa}$ at the worst location (SB2-N4) o $\mathrm{f}$ the southbound Kishwaukee Bridge. This means the shear steels are still in the safe regi on of stress-strain curve. However, more strict regulations should be encouraged so that $n$ o overweight truck passes over the bridge which might induce failure.

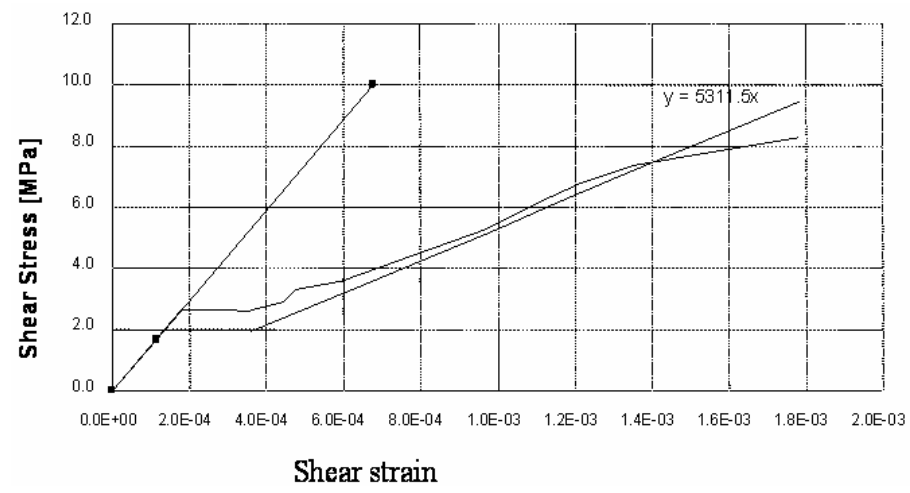

Figure 6 Relationship of shear stress and shear strain 


\section{Real-time global and local health evaluation}

Kishwaukee bridge monitoring system has been collecting and processing data an d generating evaluation and health reports for three years. The system can analyze the fre quency distribution, crack opening displacement, shear strain in the web, and traffic infor mation for the Kishwaukee Bridge. Automated warning/alarm system is in effect to warn against any local structural damage on the bridge, system problems, sensor dysfunction, a nd data errors.

After establishing the baseline of bridge health, a long-term monitoring system can be used to provide the continuous health information of a bridge. For concrete bridges, cracks, especially the shear cracks act as the main role of local damages. And the global health information of a bridge can be represented with the bridge stiffness. Both global and local conditions of bridges need be evaluated in order to determine their in-service behavior and justify rehabilitation and repair plans. The global health information can be provided by dynamic measurement, while the local damage can be captured by static type of sensors such as strain gages, linear variable displacement transducer (LVDT), etc. The raw acceleration data are collected and preprocessed to obtain the natural frequencies in a sensor substation. Then the acceleration and frequency data are transferred into the database server via the internet in real time, as shown in Figure 7(a). After that, the application server will analyze the data to get the hourly bootstrap mean and its confidence intervals, as shown in Figure 7(b).

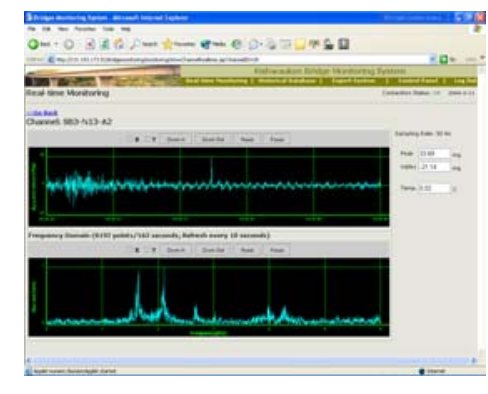

(a) Real-time acceleration \& frequencies

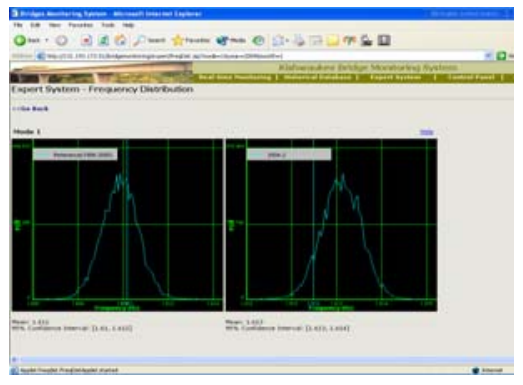

(b) Bootstrap distribution of frequencies

Figure 7 Pre-processing and post-processing of acceleration and frequencies

Based on the five dynamic tests from 1999-2000, the global dynamic characteristics of the bridge are obtained from the acceleration data with the related temperature values. Those structural parameters are setup as the baseline of global health assessment. Temperature has a significant influence on the natural frequencies of a structure. Hence it is important to derive the relationship between temperature and natural frequencies, i.e., how much the frequency will change due to the variation of $1 \mathrm{oC}$. To a certain degree, this relationship can represent the change of the bridge bending stiffness due to the temperature variation. 


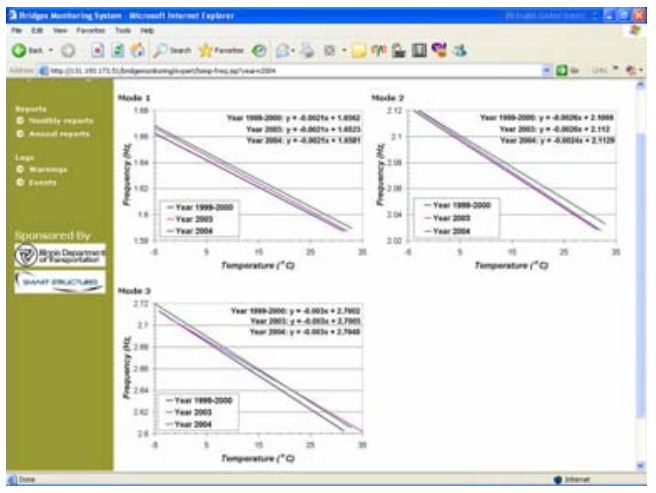

Figure 8 Relationship between temperature and first three modes

Figure 8 provides the temperature-related regression curves and parameters of the first three modes from year 1999 to year 2004. As shown in the figure, the changes of th e first two modes due to the variation of 1 oC during 2004 are almost the same as the bas eline (1999-2000). However, the analysis about mode 3 during year 2004 shows a little in crease in the frequency change due to the unit temperature variation.

According to the theory of dynamic analysis, the changes of higher modes usually reflect the development of local damages. In order to verify the result of global health assessment and inspect the state of local damage, it is necessary to carry out the specific local health evaluation.

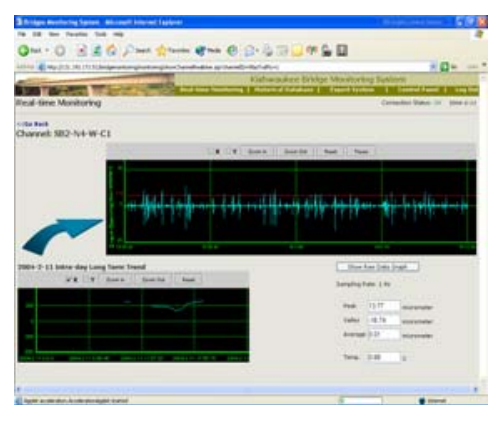

(a) Real-time Crack Opening Displacement

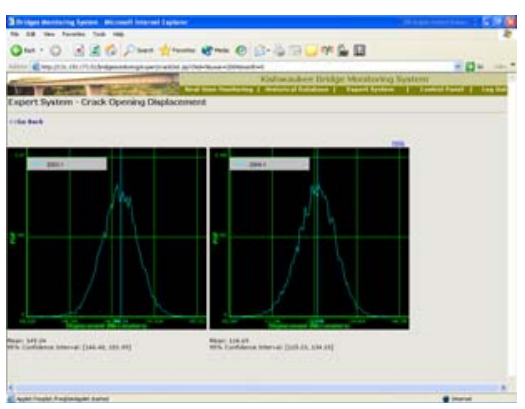

(b) Bootstrap Distribution of COD

Figure 9 Pre-processing and post-processing of crack opening displacement

The raw data of crack opening displacement (COD) are preprocessed in sensor su bstation and transferred into the database server via the internet, as shown in Figure 9(a). Then based on the hourly record of crack opening displacements, the application server w ill analyze those data to obtain their bootstrap distribution and confidence intervals. The $r$ esult is shown in Figure 9(b). 
In order to find out whether the shear cracks propagated during year 2003, it is ne cessary to analyze the relationship between temperature and crack opening displacements , i.e., to find how much the crack opening displacement will change due to a variation of $1 \mathrm{oC}$. To a certain degree, this relationship represents the change of shear stiffness of the webs due to the temperature variation.

Based on the data of these two years, the analysis result of crack opening displacements is given in Figure 10 according to their locations. During the last three years, the crack opening displacements due to temperature show some difference between the west web and the east web. As shown in the graph, on the west web, the crack opening displacement increased at the rate of about 1 micrometer per year. But on the east web of SB2-N4, the corresponding parameters are almost the same as before. The difference between the west web and the east web is possibly due to the heavier traffic on the west side of the bridge. This result conforms to the visual inspection of Illinois Department of Transportation. According to the analysis on crack opening displacement, we can evaluate the average shear strain of the cracking webs.

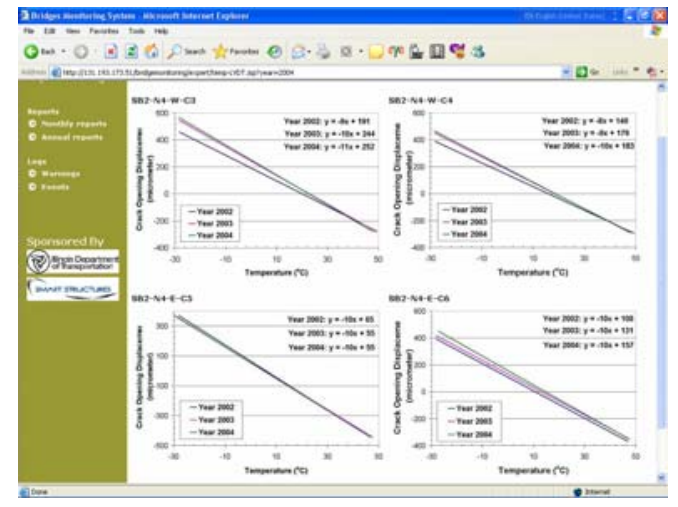

Figure 10 Relationship between crack opening displacement and temperature

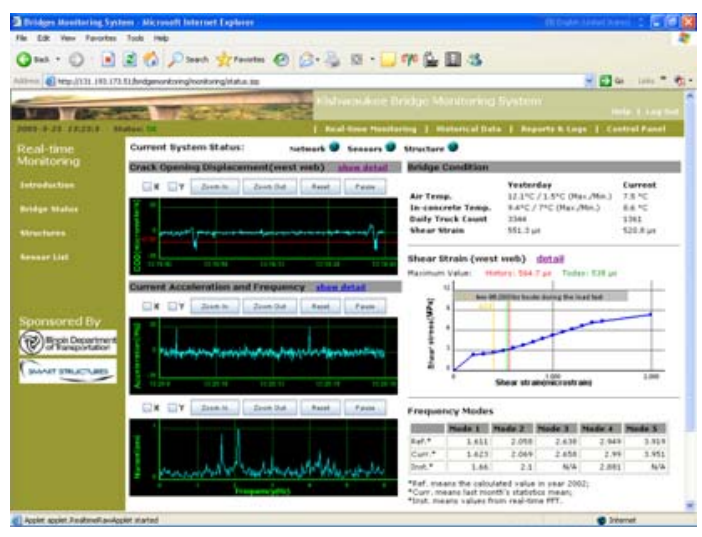

Figure 11 Main Interface of DIBMS 
Based on the global and local measurements, the rule-based expert system gives the shear carrying capacity of the bridge with ductile mode of failure. Figure 11 presents the shear stress - shear strain curve of the cracked web at Segment SB2-N4. As shown in the graph, the monthly maximum shear strain is over the baseline of the static load test in 2000. However, this value is still far below the yielding point. It indicates that the most damaged segment (SB2-N4) is still working in the nonlinear-elastic zone.

\section{Other APPLICATIONS}

Kamikazue viaduct is a double box girder PC bridge, which is formed by connecti ng two single box girder pre-cast segments. This bridge consists of 1040 segments in a s pan of 17 continuous box-girders, has a length of $630 \mathrm{~m}$ and a width of $16 \mathrm{~m}$. The segme nts are erected by span-by-span method using movable false-work. The segments are joi nted using epoxy resin and post-tensioned with external tendons in each span, as shown $\mathrm{i}$ n Figure 16.

The construction of this viaduct by utilizing pre-cast segmental construction and $\mathrm{p}$ ost-tensioning to provide large capacity external tendons was a construction technology c hallenge due to rare experience for such construction type. Therefore, a full-scale model test was carried out to verify the safety performance of the anchorage blocks and deviator $\mathrm{s}^{24}$. Besides verifying the safety of the each part, the frictional effect between the deviator and the post-tensioned tendon was also investigated.

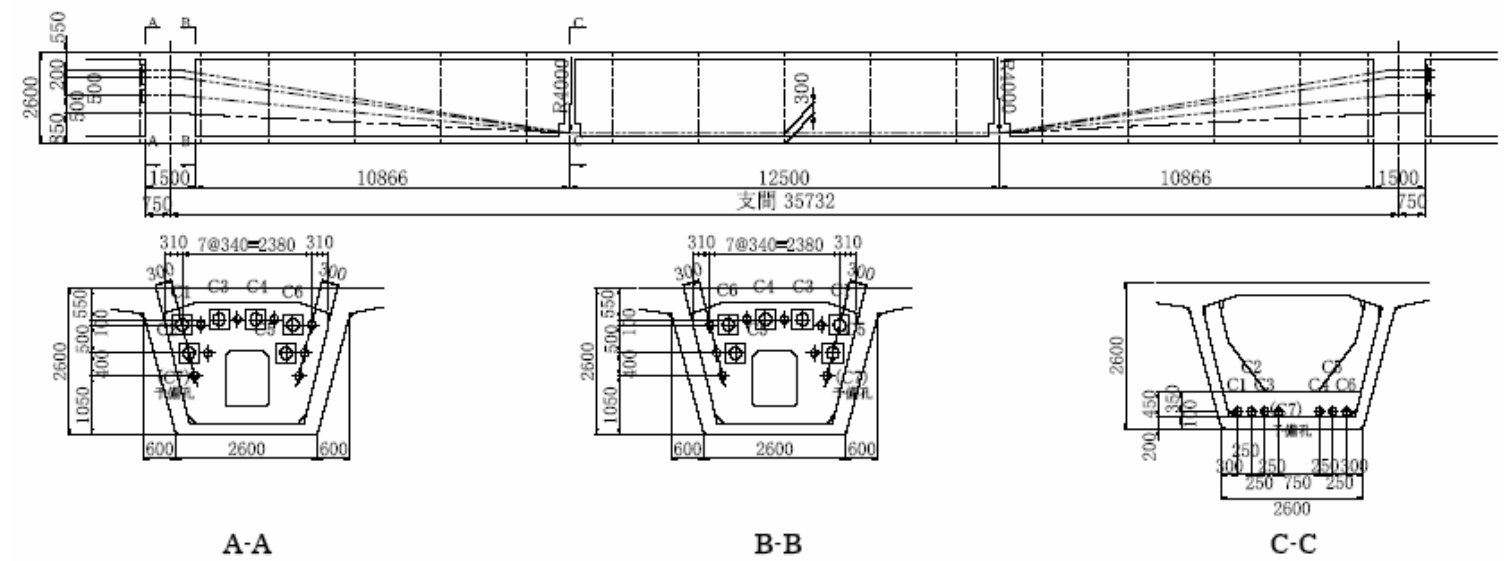

Figure 16 Stresses monitoring of post tensioning cables.

The verification test was conducted by measuring the tendon forces at either side of the deviator. Then the friction coefficient was calculated from the different stresses of the post-tensioned tendon located between these symmetrical adjacent sides of deviator. 

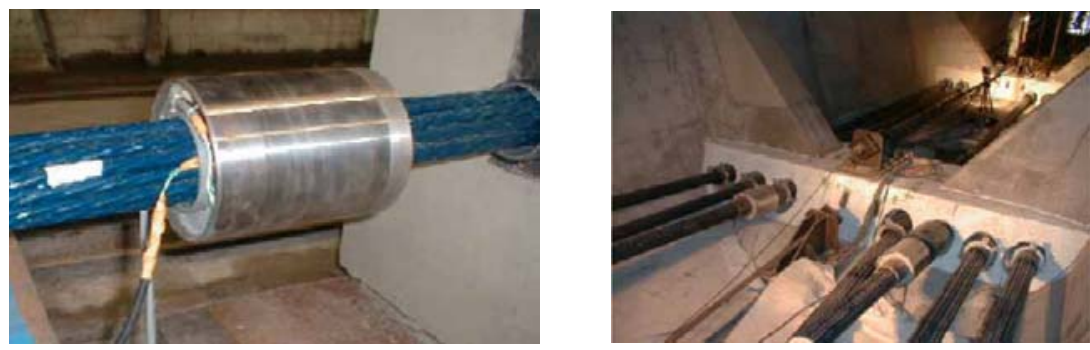

Figure 17 Calibration and installation monitoring system

The most commonly used method to measure the post-tensioning tendon stress is by attaching strain gages to the strands that form the tendons. However, this method is not applicable in this case since the epoxy-coated strands are used for external tendons. Therefore, elasto-magnetic (EM) sensor sensory technology was adopted. Verification test and calibration were conducted as shown in Figure 17 to verify changes in magnetic properties with respect to stress and temperature changes.

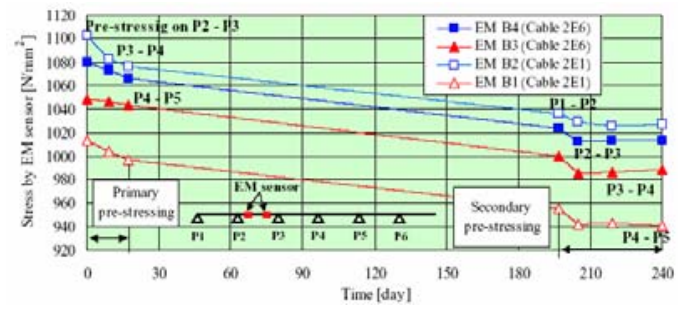

Figure 18 Long term monitoring result by EM sensor at span P2-P3

As verified by the field measurements, besides obtaining conclusive friction coeff icient of the new polyethylene covering sheath material, the stress loss due to set-loss at $f$ ixation stage, relaxation, creep and shrinkage, and elastic deformation effects were clearl y observed. Pre-stress losses in a life-cycle time of external PC bridge are significantly af fected by concrete creep, concrete shrinkage and steel tendon relaxation. It was confirme $\mathrm{d}$ in previous laboratory tests that EM sensory technology can measure the actual stress at PC tendon and relaxation.

This bridge test was conducted to verify the capability and reliability of EM sensory technology for long-term structural health monitoring on external tendon PC bridge using pre-fabricated sensors and site-fabricated sensors. To better resemble a real application on an existing bridge, stresses measured by site-fabricated sensors at span P2-P3 within 240 days from May 2002 to January 2003 were used and is illustrated in Figure 18. The long-term pre-stress losses were observed in a period between primary pre-stressing within span P2-P3 and secondary pre-stressing in the adjacent spans. Pre-stress losses were clearly observed, which was caused by elastic deformation from secondary pre-stressing. The average prestress losses in the period between primary pre-stressing and secondary prestressing (180 days) is $41.2 \mathrm{~N} / \mathrm{mm}^{2}$ and $43.1 \mathrm{~N} / \mathrm{mm}^{2}$ for 
tendons 2E1 and 2E6, respectively. These values are in good agreement with the considered design of pre-stress losses, i.e. $20.0 \mathrm{~N} / \mathrm{mm}^{2}$ prestress losses due to concrete elastic deformation and $20.0 \mathrm{~N} / \mathrm{mm}^{2}$ pre-stress losses due to concrete creep and shrinkage.

\section{Conclusion}

A real-time bridge monitoring system includes a real-time data acquisition, a realtime data analysis, and a health reporting system. It should provide the current health stat us of the bridge in real-time. It should be able to determine the current strength and resist ant capacity of a structure. The key point is to use the minimum number of sensors to coll ect, process, and analyze the real-time dynamic and static data from the most critical posi tions of the bridge.

A large-scale real-time monitoring system can generate huge amount of data ever $y$ day. The excessive information will overwhelm and decrease the productivity of the bri dge engineers if there is no any integrated program of data preprocessing and health diag nosis in the monitoring system. All the real-time raw data shall be pre-processed in the br idge to increase the speed of data transmission, save the capacity of database, and improv e the efficiency of health assessment.

Automatic measurements should not be considered to be the be-all and end-all of bridge health monitoring. Its place is firmly entrenched in assisting engineers to conveniently carry out the damage detection, analysis, and evaluation of bridges.

\section{Acknowledgments}

The authors gratefully acknowledge the initiation and continuous support in funding from the Illinois Department of Transportation, US National Science Foundation and Smart Structure Inc. Additional assistance from Dr. Sumitoro at Keisoku Research Consultant, Co. in Japan, Dr. M. Chandoga and Dr. J. Halvoník at Slovak University of Technology in Bratislava is greatly appreciated.

\section{References}

1. DeWolf, J., T. Descoteaux, J. Kou, R. Lauzon, D. Mazurek, and R. Paproski. "Expert Systems for Bridge Monitoring." Computing in Civil Engineering: Proceedings of the Sixth Conference, p. 203-210, American Society of Civil Engineers, Atlanta, GA, 1989

2. DeWolf, J., R.G. Lauzon, Y. Fu, and T.F. Lengyel, “Long-Term Monitoring of Bridges in Connecticut for Performance Evaluation of Structures.” Performance of Structures: From Research to Design, 2002 Structures Congress, p. 195-196, American Society of Civil Engineers, Denver Colorado, 2002. 
3. Carder DS, Observed vibrations of bridges. Bulletin, Seismological Society of America, vol. 27, 267-303, 1937.

4. Catbas FN, Grimmelsman KA, Aktan AE, Structural identification of the Commodore Barry Bridge. Proceedings of SPIE vol. 3995, 84-97, 2000.

5. Cheung M. S., Tadros G. S., Brown J., Dilger W. H., Ghali A., Lau D. T., Field monitoring and research on performance of the Confederation Bridge. Canadian Journal of Civil Engineering Vol. 24, 951-962, 1997.

6. Ashkenazi V., Roberts G. W., Experimental monitoring of the Humber Bridge using GPS. Civil Engineering, Proc ICE 120 177-182, 1997.

7. Bampton M. C. C., Ramsdell J. V., Graves R. E., Strope L. A., Deer Isle-Sedgwick suspension bridge. wind and motion analysis, Report FHWA/RD-86/183, 1986.

8. Barr I. G., Waldron P., Evans H. R., Instrumentation of glued segmental box girder bridges. Monitoring of Large Structures and Assessment of their Safety. IABSE Colloquium Bergamo, 1987.

9. Brownjohn J. M. W., Bocciolone M, Curami A, Falco M, Zasso A, Humber Bridge full-scale measurement campaigns 1990-1991. JWEIA 52 185-218, 1994.

10. Lau CK, Wong KY, Design, construction and monitoring of three key cable-supported bridges in Hong Kong. Proc 4th International Kerensky Conference on Structures in the new millennium, Hong Kong, 105-115, 1997.

11. Leitch J, Long A E, Thompson A, Sloan T D, Monitoring the behaviour of a major box-girder bridge. Structural Assessment Based on Full and Large-Scale Testing, BRE Garston 212-219, Butterworths, 1987.

12. Macdonald JHG, Dagless EL, Thomas BT, Taylor CA, Dynamic measurements of the Second Severn Crossing. Proc, ICE, Transport, 123, no. 4, 241-248, 1997.

13. Miyata T, Yamada H, Katsuchi H, Kitagawi, 2002, Fullscale measurement of Akashi-Kaikyo Bridge during typhoon, JWEIA 90, 1517-1527.

14. Vincent, G. S. (1958) "Golden Gate Bridge Vibration Study," ASCE Journal of the Structural Division, 84(ST6).

15. Wang M. L., etc., "Health Assessment of the Kishwaukee River Bridge.” Technical Report to IDOT, University of Illinois, April, 2001.

16. Lloyd, G., M. L. Wang, and X. Wang, "Thermo-mechanical Analysis of Long-term Global and Local Deformation Measurements of the Kishwaukee Bridge Using the Bootstrap.” Earthquake Engineering and Engineering Vibration, Vol. 3, No. 1, p. 107-115, June, 2004.

17. Lloyd, G., M. L. Wang, and X. Wang, "Thermo-mechanical Analysis of the Kishwaukee Bridge from global and local deformation measurements.” Sensors and Smart Structures Technologies for Civil, Mechanical, and Aerospace Systems, Shih-Chi Liu, Vol. 5391, p. 618-623, SPIE, San Diego, 2004.

18. Lloyd, G., M. L. Wang, and X. Wang, "Components of a Real-time Monitoring System for a Segmental Pre-cast Concrete Box Girder Bridge”, Structural Materials Technology (SMT): NDE/NDT for Highways and Bridges 2004, Buffalo, NY, 2004.

19. Lloyd, G., M. L. Wang, X. Wang, and J. Love, "Recommendations for Intelligent Bridge Monitoring Systems: Architecture and Temperature-Compensated Bootstrap 
Analysis." Smart Structures and Materials 2003: Smart Systems and Nondestructive Evaluation for Civil Infrastructures, Shih-Chi Liu, Vol. 5057, p. 247-258, SPIE, San Diego, 2003.

20. Lloyd, G., M. L. Wang, X. Wang, and J. Halvonik, "Bootstrap Analysis of Long-Term Global and Local Deformation Measurements of the Kishwaukee Bridge.” The 4th International Workshop on Structure Health Monitoring, Fu-Kuo Chang, p. 163-171, Stanford University, Stanford, 2003.

21.Wang X., M. L. Wang, Y. Zhao, H. Chen, and L. L. Zhou, "Smart Health Monitoring System for a Prestressed Concrete Bridge.” Smart Structures and Materials 2004: Sensors and Smart Structures Technologies for Civil, Mechanical, and Aerospace Systems, Shih-Chi Liu, Vol. 5391, p. 597-608, SPIE, San Diego, 2004.

22. Wang, X. and M. L. Wang, "Smart Health Monitoring System of a Prestressed Box Girder Bridge.” HK Proceedings of ICANCEER 2002, the Hong Kong Polytechnic University, Hong Kong, 2002.

23. S. Sumitro, A. Jarosevic \& M.L. Wang, "Elasto-Magnetic Sensor Utilization on Steel Cable Stress Measurement.” The First fib Congress, Concrete Structures in the 21th Century, Osaka, 13-19 October 2002, Session 15, pp.79-86, 2002.

24. S. Sumitro, T. Okamoto, S. Kurokwa, K. Shimano, K. Hida \& M.L. Wang, “Concrete Structure Health Monitoring System by Utilizing Actual-Stress-Measurement-Based”, Proc. Of Concrete under Severe Conditions: Environment \& Loading, CONSEC’04, Seoul, pp.1639-1646, 2004.

25. Guodun Wang, Ming L. Wang, Yang Zhao, Yong Chen, Bingnan Sun, "Application of EM Stress Sensors in Large Steel Cables", Smart Structures and Materials 2005: Smart Structures and Integrated Systems. Edited by Flatau, Alison B. Proceedings of the SPIE, Volume 5765, pp. 395-406, 2005. 